University of Nebraska - Lincoln

DigitalCommons@University of Nebraska - Lincoln

2-20-2001

\title{
Michaelis-Menten Kinetics for Enzymatic Depolymerization of a Linear Polyester Synthesized from Z-Protected Glutamic Acid
}

\author{
R M. Tadros \\ Pine Bluff Arsenal, Pine Bluff, Arkansas 71602 \\ Hossein Noureddini \\ Department of Chemical Engineering, University of Nebraska-Lincoln, hnouredd@unlnotes.unl.edu \\ Delmar C. Timm \\ University of Nebraska-Lincoln, dtimm1@unl.edu
}

Follow this and additional works at: https://digitalcommons.unl.edu/chemeng_biomaterials

Part of the Biomaterials Commons

Tadros, R M.; Noureddini, Hossein; and Timm, Delmar C., "Michaelis-Menten Kinetics for Enzymatic Depolymerization of a Linear Polyester Synthesized from Z-Protected Glutamic Acid" (2001). Papers in Biomaterials. 4.

https://digitalcommons.unl.edu/chemeng_biomaterials/4

This Article is brought to you for free and open access by the Chemical and Biomolecular Engineering Research and Publications at DigitalCommons@University of Nebraska - Lincoln. It has been accepted for inclusion in Papers in Biomaterials by an authorized administrator of DigitalCommons@University of Nebraska - Lincoln. 


\begin{abstract}
:
A biodegradable polyester resin was polymerized from $N$-benzyloxycarbonyl- L -glutamic acid and ethylene glycol. Rhizopus delemar lipase was used as a biocatalyst for the rupture of ester bonds during the hydrolysis studies. Depolymerization was observed to followa Michaelis-Menten mechanism, with the maximumrate of monomer formation $d P / d t_{\max }=1.12 \times 10^{-8} \mathrm{~mol} / \mathrm{s}$ and the rate constant $K_{m} \times 2.03 \times 10^{-4} \mathrm{~mol}$. Subject to initial conditions described by the most probable distribution and Michaelis-Menten-type depolymerization rate expressions, population density distribution dynamics of the polymeric molecules that formed the resin were explicitly described using a deterministic approach.
\end{abstract}

\title{
Key words:
}

Amino-protected glutamic acid; biodegradation; depolymerization; Rhizopus delemar lipase; Michaelis-Menten; polyesters

\section{Introduction}

In previous articles ${ }^{1,2}$ polymerization, characterization, and biological degradation studies of three polyesters formed from $N$-carbobenzyloxy- L-glutamic acid (ZGluOH) were reported. The polymers were a linear, heterochain polyester $(\mathrm{ZGluOH}$ and ethylene glycol), a crosslinked heterochain polyester (ZGluOH and diglycidyl ether of 1,4-butanediol), and a crosslinked heterochain aromatic polyester (ZGluOH and diglycidyl ether of bisphenol A). The three polymers were hydrolyzed to monomers using Rhizopus delemar lipase. This article reports on the kinetic analysis of enzymatic reactions between this lipase and the linear heterochain polyester. The enzyme lipase catalyzes ${ }^{3}$ the formation and in the presence of excess water the hydrolysis of ester groups. During such degradations carboxylic acid concentration in the hydrolyzing medium increases, and products of chain scission accumulate. In this study the synthesized polymer ZGluOH-ethylene glycol was subjected to hydrolysis, and the analysis of observations about the hydrolysis is reported here. The resulting catalytic action is considered an initial step in developing an understanding of the biological degradation process caused by enzymes secreted by microorganisms. Using a pure enzyme allows observation of the degradation products in solution without microbial contamination. Hydrolysis can result in chain scission and/or depolymerization. In chain scission bond rupture occurs randomly along the chain, leading to the formation of products of unequal size and of high molecular weight. In depolymerization the monomer is split from an activated chain end. Flory showed that the degradation of a polyester by ester interchange with alcohols proceeds by random rupture of ester linkages. Elias ${ }^{5}$ reported

effects of the latter on moments of the population density distribution, using derivations based on kinetic reaction analysis. Jarrett ${ }^{6}$ studied the biodegradation of high-molecular-weight polycaprolactone film (a polyester) by an enzyme and showed that the high-molecular-weight gel permeation chromatography (GPC) peak decreases in area with no discernible change in its position or distribution. These observations are consistent with depolymerization. In other experiments a shift toward lower molecular weight occurred with degradation, which suggests random chain scission. These discrepancies were attributed to the inability of the enzyme to diffuse into the polymer matrix. Therefore, results may be influenced by sample preparation and the chemical structure of the resin. Rhizopus delemar lipase has been reported to randomly split ester bonds. ${ }^{7-9}$ X-ray crystallographic studies have addressed the molecular mechanism associated with hydrolysis of lipids. ${ }^{10}$ The enzyme contains buried active centers comprised of a triad of Ser145, His258, and Asp204. Secondary loops or helixes form a "lid." When the lid is closed through conformational changes, the active center is not accessible to soluble substrates. This model is consistent with studies reported by Brady et al.," who investigated lipase purified from Rhizomucor miehei, and by Winkler et al, ${ }^{12}$ who studied human pancreatic lipase. For our work Rhizopus delemar lipase was purchased from Seilogaku Kogyo Company, Limited. Hydrolyzed products and raw materials were followed during the degradation using GPC and volumetric titration. Since different biocatalysts may have different reaction mechanisms on different substrates, we addressed two major questions: (1) Does the biocatalyst activity remain constant or does it decay during reaction times observed? and (2) Does the degradation of the tested polymer proceed by chain scission, by depolymerization, or by both? Having observed depolymerization, a theoretical chemical reaction analysis is presented to illustrate population density distribution dynamics, subject to a Michaelis-Menten reaction mechanism. 


\section{EXPERIMENTAL}

Enzymatic degradation proceeded in a stirred 50-mL Erlenmeyer flask in an aqueous medium of $\mathrm{pH} 7$ at $25^{\circ} \mathrm{C}$. The reaction mixture contained the polymer sample, Rhizopus delemar lipase, and phosphate buffer. Degradation was stopped at different time intervals by separating the suspension liquid from the unhydrolyzed solid polymer, which was subsequently washed with distilled water repeatedly to achieve separation between the unhydrolyzed polymer fraction and the enzyme. The accumulated liquid was centrifuged to remove the buffer and the enzyme. The GPC analysis characterized the hydrolyzed products, and titration measurements were used to evaluate the formation of carboxylic acid. In preparation for GPC analysis, the centrifuged liquid was dried at $70^{\circ} \mathrm{C}$ under vacuum. The dried sample and the remaining solid polymer were dissolved in $50 \mathrm{~mL}$ of tetrahydrofuran, which was the mobile phase. Approximately $0.5 \mathrm{~mL}$ of this solution was injected into the gel permeation chromatograph. The complete experimental details have been reported by Tadros et al. ${ }^{1}$ For titrations the centrifuged liquid and the remaining solid polymer were dissolved in an excess of chloroform and distilled water. Solubilities for the polymer, oligomers, and monomers resulted in partial separation between the two immiscible liquid phases. The two phases were titrated separately against $0.01 \mathrm{~N}$ potassium hydroxide, using phenolphthalein as an indicator. Clear end points occurred. Experiments were performed to test the relative rates of reaction for the enzymatic and uncatalyzed hydrolysis. In acidic or basic media, the rate of ester hydrolysis was higher than during neutral hydrolysis. ${ }^{13}$ At a $\mathrm{pH}$ of 7 the ester hydrolysis was influenced only by enzymatic activity. As a control an experiment was conducted at $\mathrm{pH}$ of 7 but without the enzyme. The carboxylic acid concentration in the hydrolyzed medium was invariant. A similar experiment with enzyme resulted in twice the original carboxylic acid content of the polymer after $14 \mathrm{~h}$ (Fig. 1). The rate of acid accumulation was linear with respect to time. It was concluded that aqueous hydrolysis was negligible compared to enzymatic hydrolysis. For this screening test the ratio of polymer to enzyme was not recorded. In experiments where the enzyme activity toward degradation was investigated, studies were conducted for $113.5 \mathrm{~h}$ with multiple flasks. The polymer had an average molecular weight of 5300 and was in the physical form of a block. The enzyme:polymer weight ratio was 0.15 . The carboxylic acid concentration was quantified initially and at specified time intervals. To one of the flasks after $95.5 \mathrm{~h}, 153 \%$ of the initial weight of the polymer was added. The polymer addition allowed for an examination of the enzyme's activity. At the time of the addition the original polymer had visually disappeared. The flask's acid content was quantified after an additional $18 \mathrm{~h}$. The results yielded are shown in Figure 2. In another set of experiments, data were interpreted in terms of the enzymatic degradation mechanism, and rate constants were calculated. The polymeric material used in this experiment had an average molecular weight of 3500 and was prepared as a powder at low temperature. Polymer weights ranged from 30 to $200 \mathrm{mg}$, while the enzyme weight was a constant $7 \mathrm{mg}$. For each specified weight several flasks were prepared. Enzymatic hydrolysis was observed for $16 \mathrm{~h}$. The resulting analysis incorporated the rate of increase in the concentration of carboxylic groups and the initial moles of ester moieties. Observations appear in Figures 3 and 4. Experiments also explored the form of chain scission. Each flask contained $75 \mathrm{mg}$ of the powdered $3500 \mathrm{MW}$ polymer sample, $7 \mathrm{mg}$ of the enzyme, $20 \mathrm{mg}$ of phosphate buffer, a $\mathrm{pH}$ of 7, and $20 \mathrm{~mL}$ of distilled water. Samples were collected immediately and after 7 and $12 \mathrm{~h}$, all of which were subjected to GPC analysis. Observations appear in

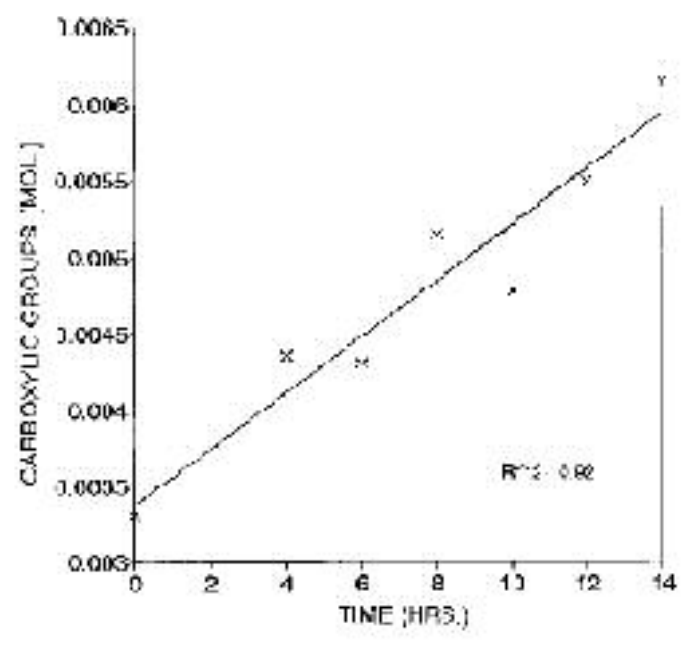

Fig.1 Enzymatic ester hydrolysis 
M. TADROS, H. NOUREDDINI, D. C. TIMM. Michaelis-Menten Kinetics for Enzymatic Depolymerization of a Linear Polyester Synthesized from Z-Protected Glutamic Acid. http://www3.interscience.wiley.com/cgi-

bin/abstract/77004008/ABSTRACT

Figure 5.
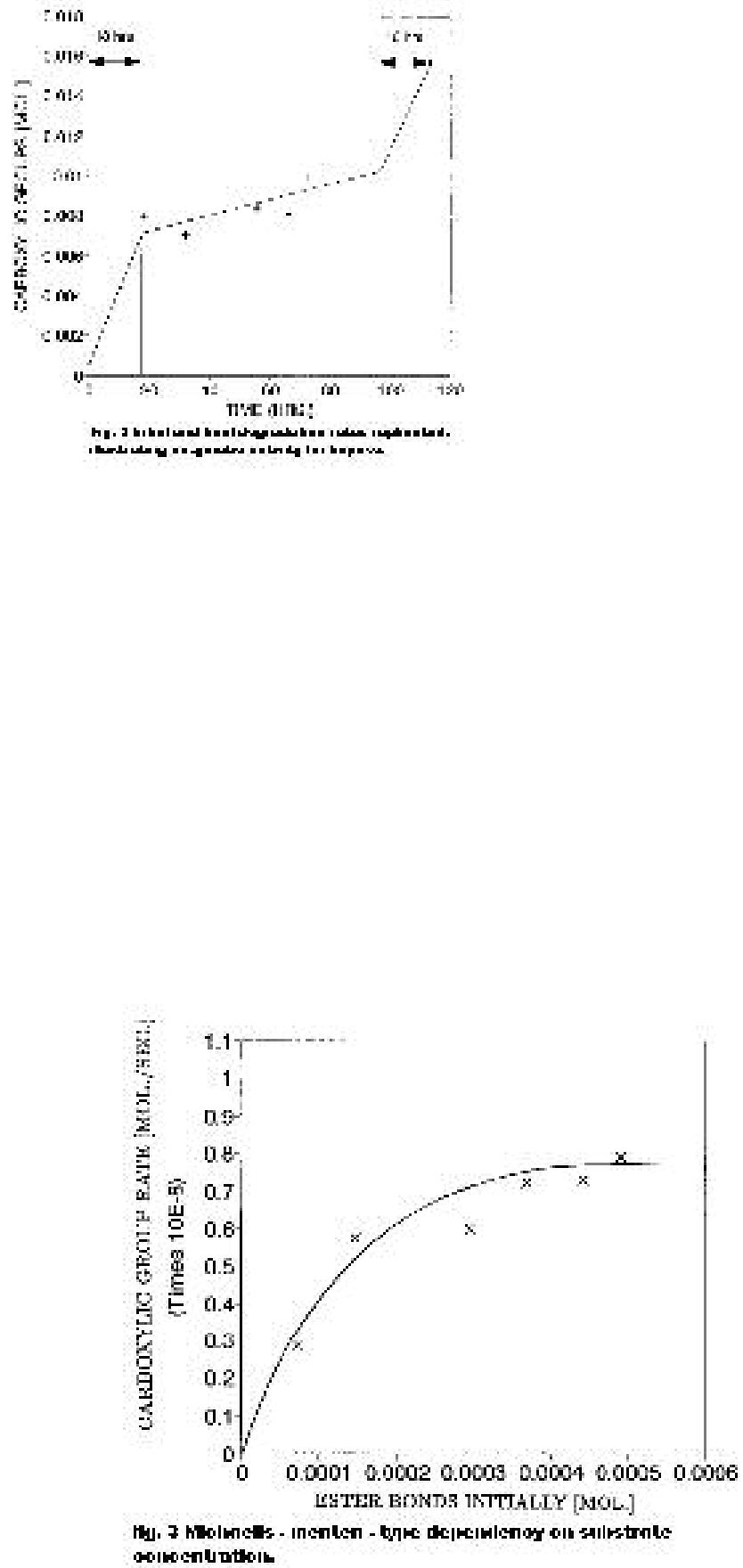
M. TADROS, H. NOUREDDINI, D. C. TIMM. Michaelis-Menten Kinetics for Enzymatic Depolymerization of a Linear Polyester Synthesized from Z-Protected Glutamic Acid. http://www3.interscience.wiley.com/cgi-

bin/abstract/77004008/ABSTRACT
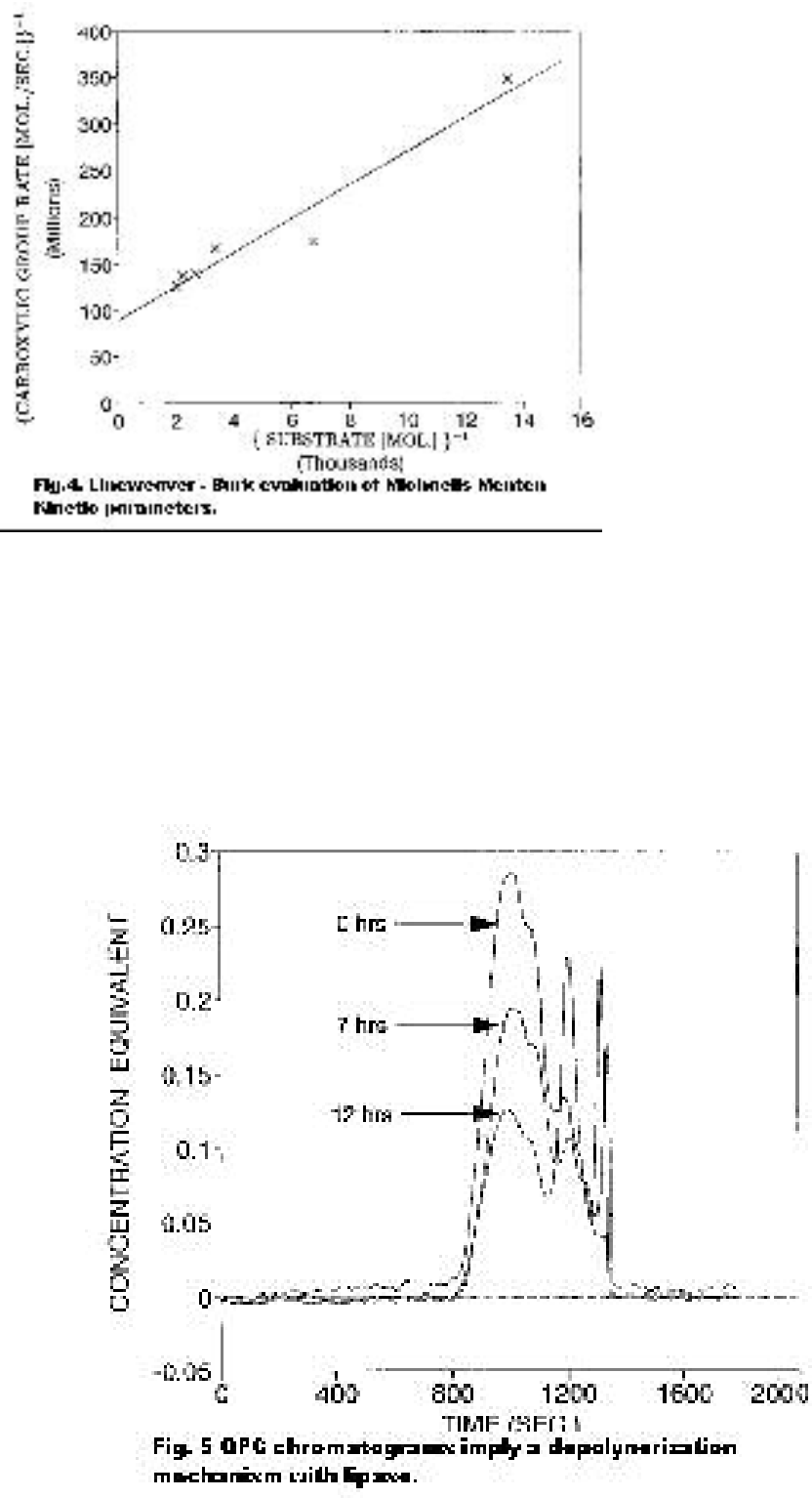


\section{TADROS, H. NOUREDDINI, D. C. TIMM. Michaelis-Menten Kinetics for Enzymatic Depolymerization of a Linear Polyester Synthesized from Z-Protected Glutamic Acid. http://www3.interscience.wiley.com/cgi- bin/abstract/77004008/ABSTRACT}

\section{Enzyme Activity}

In an initial screening test the enzymatic hydrolysis of the linear heterochain polyester led to an increase in the carboxylic acid concentration in the degradation medium, as shown by Figure 1. Experiments were then conducted to explore the activity of the enzyme. In Figure 2 the carboxylic acid content is correlated with exposure time for a gram of the polymer sample and an enzyme concentration of $3.33102^{6} \mathrm{~mol}$ at room temperature and at a $\mathrm{pH}$ of 7 . In the first $18 \mathrm{~h}$ the acid content increased rapidly, but for the next $77.5 \mathrm{~h}$ the rate diminished. The low growth period could result from lost enzyme activity or from the substrate becoming limiting and thereby controlling the degradation rate. To make a determination, an additional $153 \%$ of the $5300 \mathrm{MW}$ polymer was added at $95.5 \mathrm{~h}$, and the flask's carboxylic acid content was observed after an additional $18 \mathrm{~h}$. The acid concentration increased essentially at the initial rate. Therefore, the enzyme activity can be considered to be constant during this period.

\section{Degradation Mechanism}

The catalytic action of the enzyme is considered heterogeneous since the enzyme exists in a separate solid phase. The enzyme is adsorbed on the substrate's wetted surface. The reaction proceeds; products are released to the hydrolyzing medium, while the enzyme becomes free for subsequent reactions. In these experiments the enzyme concentration was maintained constant, while different weights of the 3500MWpolymer powder were used. The rate of carboxylic acid formation at each weight of the polymer sample was observed and is reported in Figure 3. Sample mass is expressed in terms of the number of ester bonds present. Initially, an increase in the substrate concentration resulted in an increase in the rate of hydrolysis until the substrate became in excess. Any additional increase in the substrate concentration had little effect on these initial reaction rates. This hyperbolic profile was modeled by a Michaelis-Menten kinetic mechanism. ${ }^{14}$ Michaelis and Menten ${ }^{15}$ assumed that the enzyme, $E$, and the substrate, $S$, form an activated intermediate enzyme-substrate complex $(E S)$. The forward rate constant is $k^{1}$, and the reverse rate constant is $k^{2}$. In the presence of excess water the complex breaks down, yielding the product, $P$, and releasing the enzyme. The product of the rate constant and the water concentration is expressed by $k^{3}$. The reaction mechanism is represented by

$$
\mathrm{E}-\mathrm{S} \stackrel{\mathrm{z}_{1}}{=} \mathrm{n} \stackrel{\mathrm{n}_{1}}{\rightarrow} \pi-\mathrm{P}
$$

Subject to a quasi-steady-state assumption regarding the intermediate complex (ES), the rate of product formation is expected to follow

$$
\frac{d P}{d t}=\frac{k_{3} E_{T} S}{S+K_{m}}
$$

where the rate constant, $K_{m}$, is $\left(k^{2} 1 k^{3}\right) / k^{1}$; and the molar concentration of enzyme initially formulated $\left(E_{T}\right)$ is $E 1(E S)$, the sum of the free and associated enzyme. At high substrate concentration, $S>>K_{m}$, the maximum rate of reaction will be independent of the substrate concentration:

$$
\frac{d P}{d t_{\max }}=k_{3} E_{T}
$$




\section{TADROS, H. NOUREDDINI, D. C. TIMM. Michaelis-Menten Kinetics for \\ Enzymatic Depolymerization of a Linear Polyester Synthesized from Z-Protected \\ Glutamic Acid. http://www3.interscience.wiley.com/cgi- \\ bin/abstract/77004008/ABSTRACT}

Enzyme molecules become saturated with substrate, as the linear correlation of data in Figure 1 illustrates. Although this experiment was used as an initial screening and the ratio of polymer to enzyme was not recorded, results are consistent. In a batch reactor the product of hydrolysis - the carboxylic acid-will increase linearly with time. At low substrate concentration, $S<<K_{m}$, the rate of product formation simplifies to

$\frac{d \rho}{d t}=k, E, S / K_{\mathrm{io}}$ (4)

Observations consistent with eqs. (3) and (4) are graphed in Figure 3. At low substrate concentrations (near $30 \mathrm{mg}$ polymer/7 mg enzyme), the rate of hydrolysis increased substantially with substrate concentration. At high ratios, near $200 \mathrm{mg}$ polymer/7 mg enzyme, the rate of acid formation increased relatively little with an increase in substrate content. The maximum rate of product formation was $d P / d t_{\max }=1.12 \mathrm{X} 10^{-8} \mathrm{~mol} / \mathrm{s}$, and the rate constant was $K_{m}=2.03 \times 10^{-4}$ mol. Calculations incorporated the linearized LineweaverBurk $^{14,15}$ form of eq. (2), as expressed in eq. (5). Data are correlated in Figure 4:

$$
\frac{1}{d P / d t}=\frac{1}{d P / d t_{\max }}\left(1+\frac{K_{m}}{S}\right)
$$

The preceding is considered a differential analysis. Solutions may also be obtained through integration. An integral analysis yields an implicit expression for the substrate concentration as a function of time:

$S+K m \ln S=S(0)+K m \ln S(0)-k_{3} E_{T}^{t}$

\section{Polymer Degradation Mechanism}

The enzymatic degradation of the linear polymer was extended for $12 \mathrm{~h}$. At the time of sampling the remaining polymer plus hydrolyzed products were subjected to GPC analysis. Illustrative chromatograms are presented in Figure 5. Monomers eluted between 1100 and $1300 \mathrm{~s}$ and the polymer between 800 and $1100 \mathrm{~s}$. Throughout the extent of hydrolysis there was no discernible change in the elution position of the polymer fraction. The depolymerization led to a relatively invariant number of polymer molecules per unit polymer mass. Monomer concentration increased substantially. The enzymatic-catalyzed reactions with the powdered resin resulted in the release of monomers through preferential reactions with ester groups at chain ends.

\section{Mathematical Modeling of Depolymerization Kinetics.}

Predictions are now made about the molar distribution of polymeric molecules that comprise the resin prior to and during depolymerization.

\section{Initial Conditions}

A bifunctional acid was initially polymerized with a bifunctional alcohol, forming a linear polymer comprised of molecules of molar concentration, $P_{k}$. Flory ${ }^{16}$ and Stockmayer ${ }^{17}$ have shown that, subject to equal initial molar concentrations and equal chemical reactivities for the functional groups, the resulting polymeric distribution will be described by the most probable distribution:

$P_{k}=P_{1}(0)(1-\mathrm{p})^{2} P^{k-1}$

where $\mathrm{r}$ is the conversion of functional groups, $P_{1}(0)$ is the initial monomer concentration, and $k$ is the degree of polymerization. This equation describes expected initial conditions for our resin.

\section{Depolymerization Dynamics}




\section{TADROS, H. NOUREDDINI, D. C. TIMM. Michaelis-Menten Kinetics for \\ Enzymatic Depolymerization of a Linear Polyester Synthesized from Z-Protected}

Glutamic Acid. http://www3.interscience.wiley.com/cgi-

bin/abstract/77004008/ABSTRACT

The depolymerization of polymeric molecules may be represented by the sequence of events

$P_{i} \rightarrow P_{i-1}+M \rightarrow P_{i-2} 1+2 M \cdots$

Macromolecules of degree of polymerization $I$ were arbitrarily assumed to be the largest ones initially present within the resin. Each hydrolysis reaction forms a monomeric molecule, $M$, and decrements degree of polymerization. The enzyme participates in a set of parallel reactions that involve all polymeric molecules $\left(\sum_{j=2}^{i}{ }_{j}{ }_{j}\right)$ in the resin. Since the ends of all molecules have similar chemical structures, their ability to penetrate the lid of the enzyme is expected to be similar. Therefore, constants $k_{3}$ and $K_{m}$ are expected to be independent of degree of polymerization. Subject to Michaelis-Menten kinetics, the cumulative concentration of the enzyme-polymer intermediate is

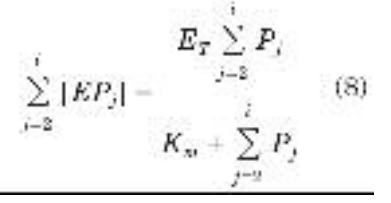

Next, emphasis is placed on molecules within the resin with degree of polymerization $k$, whose reactions can be described by

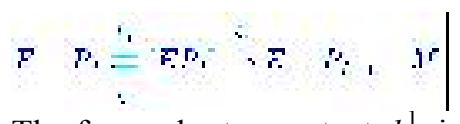

The forward rate constant, $k^{1}$, incorporates the stoichiometry coefficient 2 associated with both chain ends, which are equally reactive. The term $k^{3}$ continues to equal the product of the water concentration, which is in excess, and the rate constant associated with product formation. The quasi-steady-state approximation for the activated intermediate leads to the expression

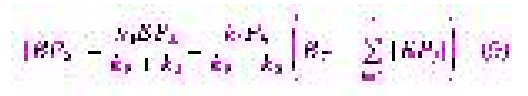

which is valid for all polymeric molecules in the resin. Subject to eqs. (8) and (9), the largest molecules are expected to decay at a rate expressed by

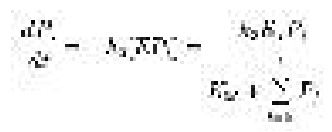

The initial condition $P(0)$ is expressed by eq. (7), subject to both $k=i$, and the achieved initial conversion, p. Because of the relatively complex, time-dependent coefficient, a dimensionless time, $\tau$, was used in derivations:

$$
d \tau=\frac{k \cdot E_{\mathrm{\gamma}}}{\kappa_{m}+\sum_{i=2}^{i} P_{j}} d t
$$




\section{TADROS, H. NOUREDDINI, D. C. TIMM. Michaelis-Menten Kinetics for Enzymatic Depolymerization of a Linear Polyester Synthesized from Z-Protected \\ Glutamic Acid. http://www3.interscience.wiley.com/cgi- bin/abstract/77004008/ABSTRACT}

$$
\frac{d P^{2}}{d \tau}=-\psi_{i} \text { and } \xi_{2}^{\prime}=\exp (-\tau) \mu_{i}(0)
$$

For molecules $P_{i-1}$, the Michaelis-Menten mechanism results in the differential equation and solution

$$
\text { UP. ' }-T, r_{1}
$$

The general solution was obtained by induction: ${ }^{18}$

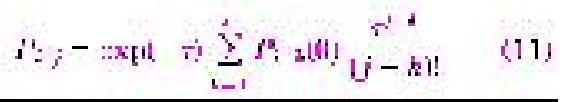

where $0 \leq j \leq i$. The monomer concentration increases according to $M-M(0)=\sum_{\mathrm{j}}^{\mathrm{i}}={ }_{2} \mathrm{j}\left[\mathrm{P}_{\mathrm{j}}(0)-\mathrm{P}_{\mathrm{j}}\right]$.

To complete the derivation, expressions are required for the cumulative number of polymeric molecules in the $\operatorname{resin} \sum_{j}^{i}=2 P_{j}=S$. An implicit solution is supplied by eq. (6). Dimensionless time, $t$, is defined by eq. (10). Experimental observations determined the constants $k_{3} E_{T}$ and $K_{m}$. Numerical integration of eq. (10), subject to eq. (6) will now yield the dependency of dimensionless time on actual time.

\section{RESULTS AND DISCUSSION}

The experimental observations in this study correlated with the Michaelis-Menten kinetic model. The dynamics of a product of depolymerization, carboxylic acid groups, were observed to be consistent when the substrate concentration was limiting, when the substrate was in excess, and when experimental conditions led to the Lineweaver- Burk analysis. GPC analysis indicated that although the polymer fraction decayed with respect to time, its relative mass distribution was invariant. Thus, the dominant degradation mechanism

resulted in the removal of monomeric units from the ends of the linear chain that forms the molecule. The enzyme's activity also remained constant during our experiments. Explicit relationships were then derived to predict the molar concentration of polymeric molecules that contain $I$ chain links as a function of dimensionless time, subject to Michaelis-Menten depolymerization kinetics. Relationships presented may be numerically integrated, yielding the correlation between dimensionless time, $t$; the initial conversion at the time of resin formation, $r$, and the time of exposure, $t$, during depolymerization studies.

Financial support from the Nebraska Soybean Development, Utilization and Marketing Board, the Center for Materials Research and Analysis, and NRI Funds for Reaction Engineering Strategies to Produce Value- Added Chemicals from Agricultural Feedstocks, University of Nebraska-Lincoln, is appreciated.

\section{REFERENCES}

1. Tadros, R. M.; Noureddini, H.; Timm, D. C. J Appl Polym Sci 1999, 73, 869.

2. Tadros, R. M.; Noureddini, H.; Timm, D. C. J Appl Polym Sci, to appear.

3. Miller, C.; Austin, H.; Posorske, L; Gonzalez, J. J Am Oil Chem Soc 1988, 65(6), 927.

4. Flory, P. J. J Am Chem Soc 1940, 62, 2255.

5. Elias, H.-G. Macromolecules, Synthesis and Materials; Plenum Press: New York, 1977; Vol. 2.

6. Jarrett, P.; Benedict, C. V. ; Bell, J. P. Mechanism of the Biodegradation of Polycaprolactone; ACS

Symposium Series 7942; Plenum Press: New York, 1983; p 181.

7. Tokiwa, Y.; Suzuki, T.; Ando, T. J Appl Polym Sci 1979, 24, 1701.

8. Tokiwa, Y.; Suzuki, T. Agric Biol 1978, 42, 1071.

9. Tokiwa, Y.; Suzuki, T. Nature 1977, 270, 76.

10. Derewenda, U.; Swenson, L.; Wei, Y.; Green, R.; Kobos, P. M.; Joerger, R.; Haas, M.J.; Derewenda, 
M. TADROS, H. NOUREDDINI, D. C. TIMM. Michaelis-Menten Kinetics for

Enzymatic Depolymerization of a Linear Polyester Synthesized from Z-Protected

Glutamic Acid. http://www3.interscience.wiley.com/cgi-

bin/abstract/77004008/ABSTRACT

Z. S. J. Lipid Research 1994, 35, 524.

11. Brady, L.; Brozozowski, A.; Derewenda, Z.; Dodson, E.; Dotson, G.; Tolley, S.; Turkenburg, J.; Christiansen,

L.; Huge-Jensen, B., Norskov, L.; Thim, L.; Menge, U. Nature 1990, 343, 781.

12. Winkler, F.; D’Arcy, A.; Hunziker, W. Nature 1990, 343, 771.

13. de Simone, V.; Maglio, G.; Palumbo, R.; Scardi, V. J Appl Polym Sci 1992, 46, 1813.

14. Foster, R. L. The Nature of Enzymology; Wiley: New York, 1980.

15. Fogler, H. S. Elements of Chemical Reaction Engineering; Prentice Hall: Upper Saddle River, NJ, 1999.

16. Flory, P. J. Principles of Polymer Chemistry; Cornell University Press: Ithaca, NY, 1953.

17. Stockmayer, W. H. J Polym Sci 1952, IX, 69.

18. Anton, H. Calculus, 2nd ed.; Wiley: New York, 1984. 